\title{
Inhibition of glycogen synthesis by increased lipid availability is associated with subcellular redistribution of glycogen synthase
}

\author{
A J Taylor ${ }^{1,2}$, J-M Ye ${ }^{1}$ and C Schmitz-Peiffer ${ }^{1,2}$ \\ ${ }^{1}$ Cell Signalling Group, Diabetes and Obesity Program, Garvan Institute of Medical Research, 384 Victoria St, Darlinghurst, NSW 2010, Australia \\ ${ }^{2}$ St Vincent's Clinical School, Faculty of Medicine, University of New South Wales, Victoria St, Darlinghurst, NSW 2010, Australia \\ (Requests for offprints should be addressed to C Schmitz-Peiffer; Email: c.schmitz-peiffer@garvan.org.au)
}

\begin{abstract}
Increased lipid availability is associated with diminished insulin-stimulated glucose uptake and glycogen synthesis in muscle, but it is not clear whether alterations in glycogen synthase activity itself play a direct role. Because intracellular localization of this enzyme is involved in its regulation, we investigated whether fat oversupply causes an inhibitory redistribution. We examined the recovery of glycogen synthase in subcellular fractions from muscle of insulin-resistant, fat-fed rats and chow-fed controls, either maintained in the basal state or after a euglycaemichyperinsulinaemic clamp. Although glycogen synthase protein and activity were mostly recovered in an insoluble fraction, insulin caused translocation of activity from the smaller soluble pool to the insoluble fraction. Fat-feeding, which led to a reduction in glycogen synthesis during the clamp, was associated with a depletion in the soluble pool, consistent with an important role for this component. A similar depletion was also observed in cytosolic fractions of
\end{abstract}

muscles from obese $d b / d b$ mice, another model of lipidinduced insulin resistance. To investigate this in more detail, we employed lipid-pretreated L6 myotubes, which exhibited a reduction in insulin-stimulated glycogen synthesis independently of alterations in glucose flux or insulin signalling through protein kinase B. In control cells, insulin caused redistribution of a minor cytosolic pool of glycogen synthase to an insoluble fraction, which was again forestalled by lipid pretreatment. Glycogen synthase recovered in the insoluble fraction from pretreated cells exhibited a low fractional velocity that was not increased in response to insulin. Our results suggest that the initial localization of glycogen synthase in a soluble pool plays an important role in glycogen synthesis, and that its sequestration in an insulin-resistant insoluble pool may explain in part the reduced glycogen synthesis caused by lipid oversupply.

Journal of Endocrinology (2006) 188, 11-23

\section{Introduction}

Skeletal muscle is an important site of insulin action, accounting for up to $70 \%$ of insulin-stimulated glucose disposal, through increased glucose uptake and glycogen synthesis. Insulin resistance in muscle is a major characteristic of type 2 diabetes, and it has become clear that the defect is strongly associated with obesity and fat oversupply (McGarry 1992). A number of mechanisms have been proposed to account for the generation of lipidinduced insulin resistance, ranging from substrate competition between lipids and carbohydrates (Randle 1998) to the activation of inhibitory signal transduction that interferes with the insulin signalling pathways stimulating glucose transport and the synthesis of glycogen (SchmitzPeiffer 2000).

Glycogen synthesis is the net result of the activities of glycogen synthase and glycogen phosphorylase. Each enzyme is regulated by phosphorylation, and activation of glycogen synthase can be explained in part by the inhibition of its phosphorylation by glycogen synthase kinase-3 (GSK-3), due to the phosphorylation and inactivation of GSK-3 itself by protein kinase B (PKB) (Cohen et al. 1997). Dephosphorylation of glycogen synthase, catalysed by type 1 protein phosphatase (PP1), is also tightly regulated. In muscle, PP1 is localized to glycogen, and hence its substrates, by association with the glycogen-targeting proteins PTG, $\mathrm{R}_{\mathrm{GL}}\left(\mathrm{G}_{\mathrm{M}}\right)$ or PPP1R6 (Newgard et al. 2000). Another mechanism by which glycogen synthase is controlled is through glucose-6-phosphate (G6P), which acts allosterically to promote full activation of the enzyme (Ferrer et al. 2003). This effect of G6P can be exploited in activity assays to indicate the total amount of glycogen synthase present.

Altered cellular localization of glycogen synthase may represent a third level of regulation, and has been reported upon insulin stimulation (Brady et al. 1999), increased glucose availability (Fernandez-Novell et al. 1992), glycogen accumulation (Nielsen et al. 2001) and alterations in 
the expression of glycogen-targeting proteins (Green et al. 2004). It appears that glycogen synthase can translocate to and from glycogen storage compartments depending on hormonal stimulation (Brady et al. 1999) and metabolic requirements, as after exercise (Nielsen et al. 2001).

Although increased lipid availability is strongly linked with inhibition of muscle glycogen synthesis, the activity of glycogen synthase itself, measured in muscle homogenates or low-speed supernatants, is not greatly affected by acute infusion of fatty acids or by high-fat feeding (Johnson et al. 1992, Kelley et al. 1993, Boden et al. 1994, Stark et al. 2000, Huang et al. 2003). However, there have been no studies of the possible link between lipid-induced insulin resistance and a change in the subcellular localization of glycogen synthase, although the inhibition of glycogen synthesis by insulin pretreatment has been associated with prior translocation of a minor pool of glycogen synthase (Jensen et al. 2000). The aim of the present study was therefore to examine the potential role of glycogen synthase compartmentalization in the adverse effects of lipids on glycogen synthesis. We first employed high-fat-fed rats and obese $d b / d b$ mice as in vivo models of lipid-induced skeletal muscle insulin resistance to demonstrate that fat oversupply did indeed result in alterations in the subcellular distribution of glycogen synthase in skeletal muscle. This was then investigated in more detail in lipid-pretreated L6 muscle cells in culture. Our data support a novel regulatory mechanism, involving the sequestration of glycogen synthase in an insulinunresponsive pool, that may account at least in part for the inhibitory effects of lipids on glycogen synthesis in skeletal muscle.

\section{Materials and Methods}

\section{Materials}

$\alpha$-Minimal essential medium (MEM $\alpha$ ) was from Trace Biosciences (Sydney, Australia). Fetal calf serum (FCS) was from Life Technologies (Gaithersburg, MD, USA). Linoleate and fatty acid-free BSA was from Sigma. Insulin (Actrapid) was from Novo Nordisk (Copenhagen, Denmark). Triton X-100 was from Roche Diagnostics (Sydney, Australia). Bicinchoninic acid (BCA) protein assay kits were from Pierce Biotechnology (Rockford, IL, USA). Antibodies to PKB and phospho-Ser-473-PKB were from Cell Signaling Technology (Beverly, MA, USA). Antibodies to PTG and protein O-linked glycosylation sites were from Santa Cruz Biotechnology (Santa Cruz, CA, USA). Glycogen synthase antibodies were a kind gift from Prof. John Lawrence, University of Virginia. L6 rat skeletal muscle cells were a kind gift from Dr Amira Klip, Hospital for Sick Children, Toronto, Canada. Other reagents were from Sigma or BDH (Merck, Kilsyth, Australia).
Animals

All experimental procedures were approved by the Animal Experimentation Ethics Committee (Garvan Institute/St Vincent's Hospital, Sydney, Australia) in accordance with the National Health and Medical Research Council of Australia Guidelines on Animal Experimentation. Wistar rats had free access for 3 weeks to either standard laboratory chow (Norco, Kempsey, Australia; $18 \%$ fat by energy content) or a high-fat diet (59\% fat) (Storlien et al. 1986). Rats were then cannulated and subjected to a euglycaemic-hyperinsulinaemic clamp with 2-deoxy-D- $\left[2,6-{ }^{3} \mathrm{H}\right]$ glucose and D-[U- $\left.{ }^{14} \mathrm{C}\right]$ glucose administration, as described previously (Oakes et al. 1994, Schmitz-Peiffer et al. 1997), the glucose infusion rate giving an indication of whole body insulin action. At the completion of the clamp, rats were killed, and tissue samples were rapidly removed and frozen in liquid nitrogen for subsequent analysis. For basal studies, no insulin or glucose infusion was administered. Measurement of muscle glycogen and triglyceride content, and estimates of the rates of muscle glucose uptake and glycogen synthesis from tissue tracer content, were done as described by Ye et al. (2003). Red gastrocnemius muscle was investigated as an example of oxidative muscle, which makes the predominant contribution to insulin-induced peripheral glucose disposal and glycogen synthesis (James et al. 1985). $d b / d b$ mice were on a C57BL/KsJ background and were fed standard laboratory chow. Fasted animals were killed by cervical dislocation, and quadriceps muscles were immediately removed and frozen in liquid nitrogen for subsequent analysis.

\section{Cell culture and lipid preincubations}

L6 myoblasts were maintained in MEM $\alpha$ and differentiated into myotubes, as described by Mitsumoto and Klip (1992). Lipid-containing media were prepared by conjugation of linoleate with BSA (Schmitz-Peiffer et al. 1999). Myotubes were preincubated for $16 \mathrm{~h}$ in MEM $\alpha$ containing $2 \%(\mathrm{w} / \mathrm{v})$ FCS in the absence or presence of $1 \mathrm{mM}$ linoleate, followed by a $2-\mathrm{h}$ period in similar volumes of serum free- (SF-) MEM $\alpha$, again in the absence or presence of linoleate.

\section{Cell and tissue fractionation and immunoblotting}

Cytosolic, solubilized-membrane and Triton-insoluble fractions were prepared from rat skeletal muscle and L6 myotubes by centrifugation and incubation with detergent by a method modified from our previous studies (Schmitz-Peiffer et al. 1997, Cazzolli et al. 2002). Briefly, dismembranated muscle was homogenized in buffer containing $20 \mathrm{mM}$ MOPS (pH 7.5), $250 \mathrm{mM}$ mannitol, $1.2 \mathrm{mM}$ EGTA, $50 \mathrm{mM} \mathrm{NaF}, 2 \mathrm{mM}$ phenylmethylsulphonyl fluoride (PMSF), $200 \mu \mathrm{g} / 1$ leupeptin and 
$2 \mathrm{mM}$ benzamidine ( $200 \mu \mathrm{l} \mathrm{buffer} / 50 \mathrm{mg}$ tissue). This and all subsequent steps were carried out at $4{ }^{\circ} \mathrm{C}$. Cells, treated in $6 \mathrm{~cm}$ dishes, were scraped into $500 \mu \mathrm{l}$ homogenization buffer and sonicated. Extracts were centrifuged at $200000 \boldsymbol{g}$ for $10 \mathrm{~min}$, and the resultant supernatant was termed the cytosolic fraction. Pellets derived from muscle tissue were washed by resuspension in homogenizing buffer and recentrifugation as above, while the much smaller cell-derived pellets were rinsed, but not resuspended and centrifuged. All pellets were then resuspended in a solubilization buffer containing $20 \mathrm{mM}$ MOPS (pH 7·5), 1\% (v/v) Triton X-100, 2 mM EDTA, 5 mM EGTA, $2 \mathrm{mM}$ PMSF, $200 \mu \mathrm{g} / 1$ leupeptin and $2 \mathrm{mM}$ benzamidine, using an equal volume to that used for homogenization. After incubation for $1 \mathrm{~h}$, suspensions were again centrifuged, and the resulting supernatants were termed solubilized-membrane fractions. The Tritoninsoluble fractions were washed or rinsed as above in solubilization buffer, and finally resuspended in an equal volume of solubilization buffer. The total protein content of extracts or cytosolic and membrane fractions was determined by BCA assay, and samples of equivalent fractions were adjusted for minor variations. For SDSPAGE, Laemmli sample buffer was added to cytosolic and solubilized-membrane fractions, which were than heated to $100{ }^{\circ} \mathrm{C}$ for $2 \mathrm{~min}$, while urea sample buffer $(8 \mathrm{M}$ urea, $1 \%$ (w/v) SDS, $100 \mathrm{mM}$ Tris (unbuffered), $150 \mathrm{mM}$ $\mathrm{NaCl}, 50 \mathrm{mM}$ EDTA and 1\% (v/v) 2-mercaptoethanol) was added to Triton-insoluble fractions, which were then incubated at room temperature for $2 \mathrm{~h}$ (Hughes \& Parker 2001). Immunoblotting and densitometry were carried out as previously described (Schmitz-Peiffer et al. 1997, 1999). To confirm equal loading between samples, membranes were stripped and reprobed with $\beta$-actin antibodies (or total PKB antibodies when phospho-Ser473-PKB was measured). Immunoblotting for $R_{G L}\left(G_{M}\right)$ was kindly carried out by the laboratory of Prof. Anna DePaoli-Roach, Indiana University (USA).

\section{Glycogen synthesis in L6 myotubes}

Lipid-pretreated myotubes in 12-well plates were incubated for $1 \mathrm{~h}$ in $0.5 \mathrm{ml} /$ well SF-MEM $\alpha$ containing D-[U${ }^{14} \mathrm{C}$ glucose $(20 \mu \mathrm{Ci} / \mathrm{ml})$ and $5 \mathrm{mM}$ unlabelled glucose, in the absence or presence of $100 \mathrm{nM}$ insulin and $1 \mathrm{mM}$ linoleate, as stated in the figure legends, and glycogen production was determined as described previously (Schmitz-Peiffer et al. 1999). To provide an estimate of the effect of linoleate on the steady state levels of glycogen, myotubes in 12-well plates were incubated for $48 \mathrm{~h}$ in $1 \mathrm{ml} /$ well MEM $\alpha$ containing 2\% (w/v) FCS and D-[U- $\left.{ }^{14} \mathrm{C}\right]$ glucose $(5 \mu \mathrm{Ci} / \mathrm{ml})$, and then overnight with the same media in the absence or presence of $1 \mathrm{mM}$ linoleate. Radiolabelled glycogen was determined as above.

\section{Glycogen synthase and phosphorylase activity assays}

Muscle samples or lipid-pretreated myotubes were fractionated as above. For the assay of glycogen synthase, adapted from Kochan et al. (1981), samples $(50 \mu \mathrm{l})$ were incubated at $30{ }^{\circ} \mathrm{C}$ with $50 \mu \mathrm{l}$ assay buffer $1(100 \mathrm{mM}$ Tris-HCl (pH 7.4), $40 \mathrm{mM}$ EDTA, $50 \mathrm{mM} \mathrm{NaF}, 1 \%$ $(\mathrm{w} / \mathrm{v})$ glycogen, $5 \mathrm{mM}$ uridine diphospho-D-[U- $\left.{ }^{14} \mathrm{C}\right]$ glucose $(1 \mu \mathrm{Ci} / \mathrm{ml})$ and either 0.3 or $10 \mathrm{mM}$ G6P). Incubations were carried out for $20 \mathrm{~min}$ and terminated by the transfer of $50 \mu \mathrm{l}$ of the reaction mixture onto a $2 \times 2 \mathrm{~cm}$ square of filter paper, which was immediately immersed in $70 \%(\mathrm{v} / \mathrm{v})$ ethanol to precipitate glycogen. Filter papers were washed twice for $30 \mathrm{~min}$, dried and counted for radioactivity. To provide an indication of the activation state of glycogen synthase, the fractional velocity of the enzyme was calculated as activity measured in the presence of $0.3 \mathrm{mM}$ G6P divided by activity measured in the presence of $10 \mathrm{mM}$ G6P. For the assay of glycogen phosphorylase, adapted from Gilboe et al. (1972), samples were incubated for $20 \mathrm{~min}$ in $50 \mu \mathrm{l}$ of either assay buffer 2 (33 mM 2-[N-morpholino] ethanesulphonic acid (MES), $15 \mathrm{mM}$ D-[U- $\left.{ }^{14} \mathrm{C}\right]$ glucose-1-phosphate $(1 \mu \mathrm{Ci} / \mathrm{ml})$ and $0 \cdot 34 \%(\mathrm{w} / \mathrm{v})$ glycogen) or assay buffer $3(33 \mathrm{mM}$ MES, $273 \mathrm{mM}$ glucose-1-phosphate $(1 \mu \mathrm{Ci} / \mathrm{ml})$ and $0 \cdot 34 \%$ $(\mathrm{w} / \mathrm{v})$ glycogen, $5 \mathrm{mM}$ AMP). Samples of the reaction mixture were spotted onto filter paper, washed and counted as above.

\section{Glucose uptake assays}

Glucose uptake was measured in the presence of $5 \mathrm{mM}$ glucose by a method adapted from Schmitz-Peiffer et al. (1999). Briefly, lipid-pretreated myotubes in 12-well plates were incubated in SF-MEM $\alpha$ in the absence or presence of insulin and linoleate, exactly as described for the determination of glycogen synthesis above, with the exception that $\left[2,6-{ }^{3} \mathrm{H}\right] 2-\mathrm{DG}(1 \mu \mathrm{Ci} /$ well $)$ was used as tracer. Cells were washed three times with ice-cold PBS and extracted in $1 \mathrm{ml} \mathrm{PBS,} 0 \cdot 05 \%$ (w/v) SDS. After incubation for $30 \mathrm{~min}$ at $37^{\circ} \mathrm{C}$, extracts were counted for radioactivity, and counts corrected for protein content.

\section{G6P assay}

Myotubes, pretreated without or with linoleate for $16 \mathrm{~h}$ and incubated in the absence or presence of insulin for $10 \mathrm{~min}$, were washed twice with ice-cold PBS and extracted with $200 \mu \mathrm{l}$ perchloric acid $(6 \% \mathrm{v} / \mathrm{v})$, and extracts were centrifuged for $10 \mathrm{~min}$ at $4{ }^{\circ} \mathrm{C}$. Supernatants were neutralized by the addition of $25 \mu \mathrm{l}$ of $500 \mathrm{mM}$ ethanolamine $(\mathrm{pH} 7)$ and $25-28 \mu \mathrm{l}$ of $10 \mathrm{M} \mathrm{KOH}$. After recentrifugation, $100 \mu \mathrm{l}$ samples of supernatants were assayed spectrophotometrically by a method adapted from Michal (1984), in a final volume of $250 \mu \mathrm{l}$ containing $50 \mathrm{mM}$ Tris- $\mathrm{HCl}$ (pH 8), 1 mM NADP ${ }^{+}, 10 \mathrm{mM} \mathrm{MgCl}_{2}$ 
Table 1 Comparison of plasma and metabolic parameters in chow- and fat-fed rats

\begin{tabular}{|c|c|c|}
\hline & Chow & Fat-fed \\
\hline Initial body weight (g) & $307 \pm 6(13)$ & $311 \pm 3(17)$ \\
\hline Final body weight $(\mathrm{g})$ & $367 \pm 3(13)$ & $368 \pm 3(17)$ \\
\hline Visceral fat weight (g) & $8 \cdot 0 \pm 0 \cdot 6(13)$ & $12 \cdot 4 \pm 0 \cdot 4(15)^{\star *}$ \\
\hline Red quadriceps muscle trigylceride $(\mu \mathrm{mol} / \mathrm{g})$ & $3 \cdot 0 \pm 0 \cdot 1(8)$ & $4 \cdot 6 \pm 0 \cdot 5(8)^{\star \star}$ \\
\hline Red quadriceps muscle glycogen content $(\mu \mathrm{mol} / \mathrm{g})$ & $29 \pm 2(7)$ & $31 \pm 1(9)$ \\
\hline $\begin{array}{l}\text { Basal } \\
\text { Plasma glucose (mM) } \\
\text { Plasma insulin (mU/l) }\end{array}$ & $\begin{array}{c}7 \cdot 9 \pm 0 \cdot 3(7) \\
38 \pm 5(7)\end{array}$ & $\begin{aligned} 8 \cdot 9 & \pm 0 \cdot 2(9)^{* *} \\
51 & \pm 5(9)^{* *}\end{aligned}$ \\
\hline $\begin{array}{l}\text { Clamp } \\
\text { Plasma glucose }(\mathrm{mM}) \\
\text { Plasma insulin }(\mathrm{mU} / \mathrm{l}) \\
\text { Glucose infusion rate }\left(\mathrm{mg} \text { per } \mathrm{kg}^{-1} / \mathrm{min}\right) \\
\text { Red quadriceps glucose disposal }\left(\mu \mathrm{mol} \text { per } 100 \mathrm{~g}^{-1} / \mathrm{min}\right) \\
\left.\text { Red quadriceps glycogen synthesis ( } \mu \mathrm{mol} \text { per } 100 \mathrm{~g}^{-1} / \mathrm{min}\right)\end{array}$ & $\begin{aligned} 7 \cdot 9 & \pm 0 \cdot 1(6) \\
108 & \pm 9(6) \\
32 & \pm 1(6) \\
30 & \pm 1(6) \\
9 & \pm 16(6)\end{aligned}$ & $\begin{aligned} 7 \cdot 4 & \pm 0 \cdot 1(9) \\
110 & \pm 12(9) \\
15 & \pm 2(9)^{\star *} \\
22 & \pm 1(8)^{\star *} \\
5 & \pm 0 \cdot 5(9)^{\star \star}\end{aligned}$ \\
\hline
\end{tabular}

Rats were fed either a standard chow or high-fat diet for 3 weeks and then subjected to a euglycaemic-hyperinsulinaemic clamp or maintained in the basal state as indicated, prior to tissue removal and extraction for the determination of tracer and metabolite content. Numbers of animals for each determination are given in parentheses. ${ }^{*} P<0 \cdot 01$ chow vs fat-fed.

and 0.2 units $/ \mathrm{ml}$ G6P dehydrogenase. The change in absorption at $340 \mathrm{~nm}, 15 \mathrm{~min}$ after addition of G6P dehydrogenase, was used to calculate G6P content from a standard curve generated using G6P standards also treated with perchloric acid and $\mathrm{KOH}$.

\section{Statistical analysis}

Calculations were performed with a commercial software package, StatView 4.5 (Abacus Concepts/Brainpower, Berkeley, CA, USA). Comparisons of two groups were performed by Student's $t$-test. Comparison of four groups was performed by two-way ANOVA. Results are presented as means \pm S.E. $P<0 \cdot 05$ was considered statistically significant.

\section{Results}

To investigate the role of compartmentalization of glycogen synthase in the generation of lipid-induced insulin resistance in skeletal muscle, we employed a wellcharacterized animal model of insulin resistance in which rats were fed a high-fat diet for 3 weeks, as previously described (Kraegen et al. 1986, Storlien et al. 1986). The diet caused accumulation of visceral fat and muscle triglyceride, which was associated with minor elevations in basal plasma insulin and glucose levels, suggestive of whole body insulin resistance (Table 1). This was confirmed by the reduced glucose infusion rate $(53 \%)$ observed during a 2-h euglycaemic-hyperinsulinaemic clamp (Table 1). Insulin resistance in muscle was indicated more directly by the reductions in muscle glucose uptake $(27 \%)$ and muscle glycogen synthesis (44\%) during the clamp (Table 1). There was no alteration in total muscle glycogen content (Table 1).

To determine the subcellular distribution of glycogen synthase, homogenates of red gastrocnemius muscles from chow- and fat-fed rats were fractionated by centrifugation and detergent solubilization to generate three compartments, referred to here as the cytosolic, solubilized-membrane and Triton-insoluble fractions. Similar protocols have been employed to study glycogen synthase translocation in response to other treatments in skeletal muscle (Nielsen et al. 2001), hepatocytes (Fernandez-Novell et al. 1992, Green et al. 2004) and adipocytes (Brady et al. 1999). The Triton-insoluble fraction (TIF) typically contains cytoskeletal elements and also glycogen. Because all fractions were generated in equivalent volumes, and equal sample sizes were assayed, the enzyme protein and activity levels observed in each fraction can be compared directly. By immunoblotting, we observed that insulin infusion reduced the recovery of glycogen synthase in the cytosolic and solubilizedmembrane fractions (Fig. 1a and b). High-fat feeding independently reduced enzyme recovery in these fractions, although insulin infusion subsequently reduced the levels further (Fig. 1a and b). There was no effect on the distribution of GSK-3. Immunoblots of glycogen synthase in the TIF were extremely smeared (Fig. 1c), indicating that despite the use of a urea-containing sample buffer for SDS-PAGE, a major proportion of the enzyme was still insoluble. The levels in this fraction could therefore not be quantified by densitometry in order to distinguish between the possibilities of enzyme translocation and enzyme depletion.

We therefore examined total glycogen synthase activity in all fractions. The activity levels observed in the 


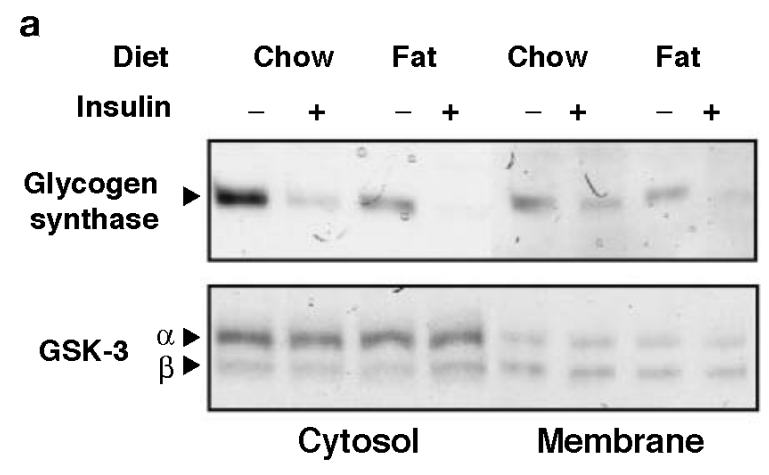

C

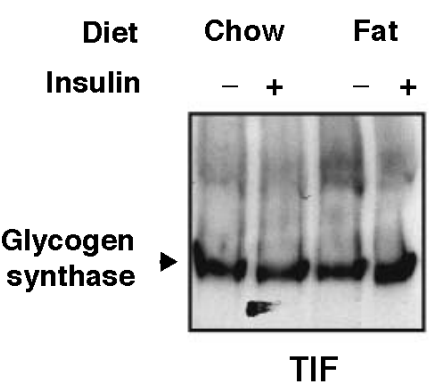

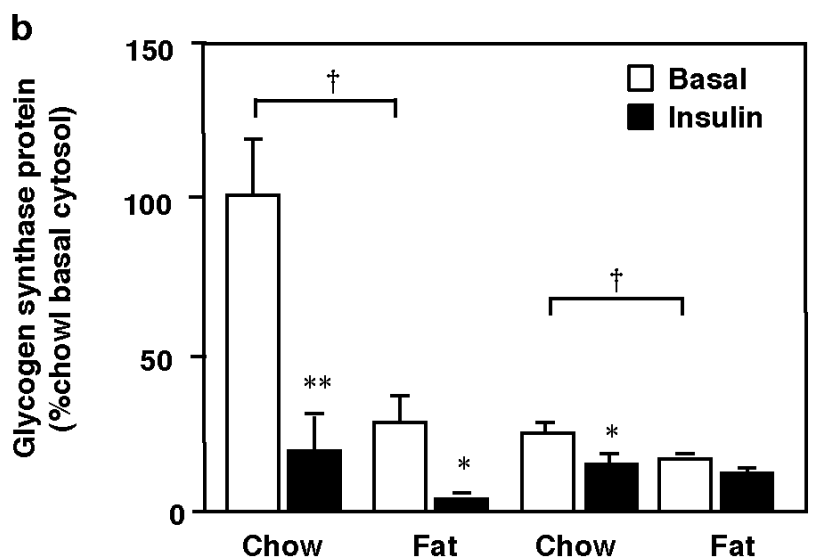

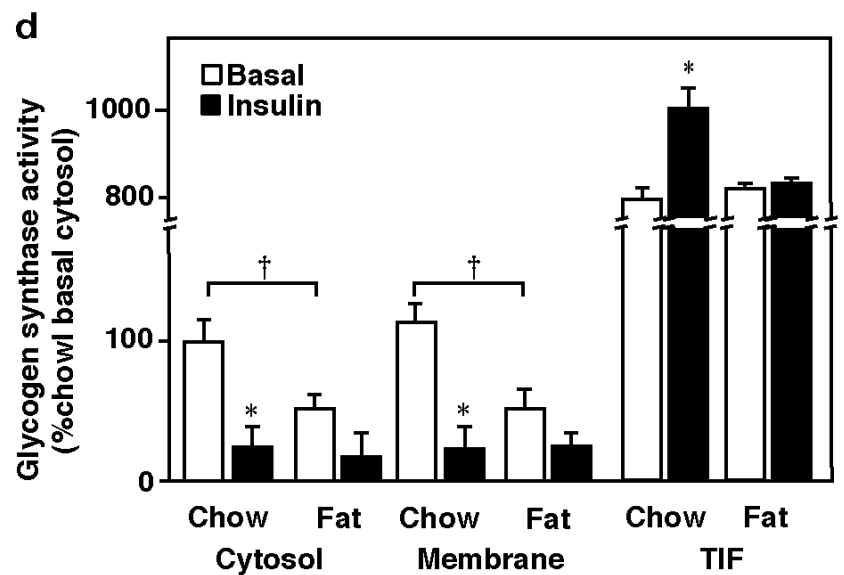

Figure 1 The effect of high-fat feeding on glycogen synthase protein partitioning in rat skeletal muscle. Rats which had been fed either a chow or a high-fat diet were subjected to a euglycaemic-hyperinsulinaemic clamp, or maintained under basal conditions, as indicated. Skeletal muscle was fractionated and subjected to immunoblotting. (a) Immunoblots obtained with glycogen synthase and GSK-3 antibodies are shown. (b) The results of densitometry of glycogen synthase bands from muscle fractions of six animals per group are shown. $t$-test, ${ }^{*} P<0 \cdot 05,{ }^{*} P<0 \cdot 01$, effect of insulin; $+P<0 \cdot 05$, effect of lipid. (c) Immunoblots of glycogen synthase in the Triton-insoluble fraction (TIF). (d) Muscle fractions from chow- and fat-fed rats were assayed for glycogen synthase activity in the presence of $10 \mathrm{mM}$ G6P to indicate the total amount of enzyme present in each fraction. The means of activities from muscle fractions of six animals per group are shown - note the discontinuous ordinate axis. $t$-test, ${ }^{*} P<0 \cdot 005$, effect of insulin; $+P<0 \cdot 01$, effect of lipid.

cytosolic and membrane fractions were consistent with the results of immunoblotting, and assays also confirmed that the major proportion of skeletal muscle glycogen synthase was indeed located in the TIF (Fig. 1d). Muscle from chow-fed control rats that had been infused with insulin exhibited elevated glycogen synthase activity in the TIF as well as a reduction in other fractions (Fig. 1d), indicating translocation of the enzyme.

Fat-feeding also reduced the total enzyme activity recovered in the cytosolic and membrane fractions from rat muscle, which was further reduced by insulin infusion, although this did not reach significance, being close to the lower limits of detection. However, there was no corresponding increase in the TIF (Fig. 1d). While this appears to argue for reduced total levels of glycogen synthase rather than translocation, the insolubility of this fraction may also have prevented an accurate determination of the total activity. In either case, however, the results are consistent with a significant role for the relatively small cytosolic and/or membrane pools of the enzyme in insulin-stimulated glycogen synthesis, and suggest that its prior depletion by increased lipid availability may contribute to the diminished glycogen synthesis observed during the clamp. Assays carried out in the presence of lower, more physiological G6P concentrations, to give an indication of the activation state of the enzyme, were difficult to interpret because of the very low activities in the cytosol and membrane fractions (not shown).

To rule out the possibility that the changes we observed in cytosolic glycogen synthase were peculiar to this dietary model of insulin resistance, we also examined the levels of the enzyme in the cytosol and TIF from quadriceps 


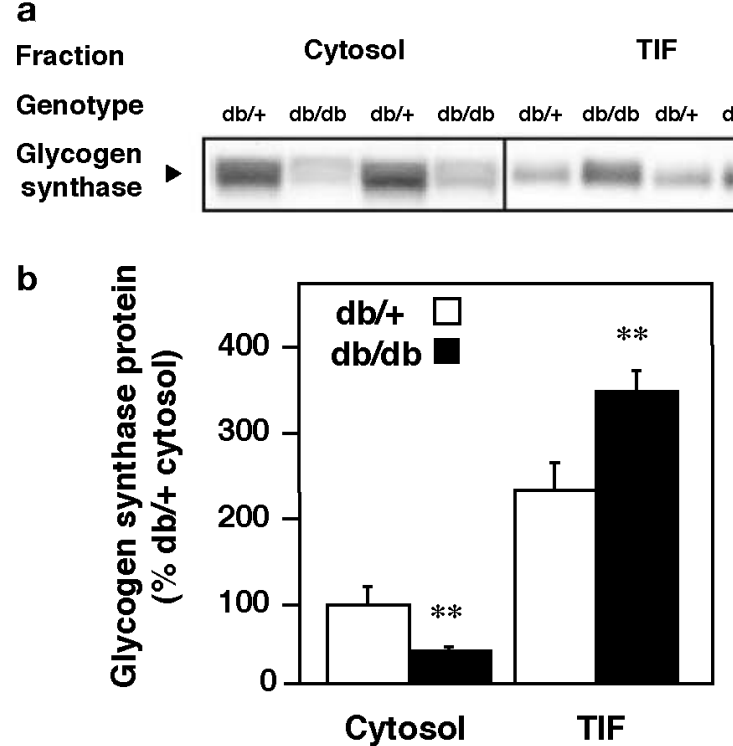

Figure 2 The $d b / d b$ mouse genotype is associated with reduced cytosolic and increased TIF levels of glycogen synthase. (a) Quadriceps muscles of obese diabetic $d b / d b$ mice and heterozygous lean control $(d b /+)$ mice were fractionated by the same procedure as muscle from fat-fed rats, and fractions subjected to SDS-PAGE and immunoblotting for glycogen synthase. (TIF fractions were diluted sixfold in comparison to cytosolic fractions.) (b) The results of densitometry of glycogen synthase bands from muscle fractions of four animals per group, corrected for dilution, are shown. $t$-test, ${ }^{*} * P<0 \cdot 02$, effect of genotype.

muscle of genetically obese $d b / d b$ mice. These animals exhibit features similar to type 2 diabetes (Coleman 1978), including muscle insulin resistance. Importantly, glycogen synthesis in muscle from $d b / d b$ mice is depressed in vivo, while glycogen synthase activity measured in whole-tissue extracts appears normal (Benzo \& Stearns 1982), consistent with the hypothesis that the in vivo action of the enzyme is dependent on its subcellular localization. Similar to the reduction in cytosolic glycogen synthase we had observed in muscles from fat-fed rats, the enzyme was reduced by more than $50 \%$ in the cytosolic fraction of muscle from $d b / d b$ mice compared with lean $d b /+$ littermates (Fig. 2). Furthermore, we were able to resolve glycogen synthase by SDS-PAGE in the TIF generated from these muscles, demonstrating that the enzyme protein level indeed increased in this fraction from $d b / d b$ muscle. These results therefore support our findings concerning muscle from fat-fed rats and extend their relevance to obesity and diabetes.

Because of the difficulties in analysing glycogen synthase in the TIF, and because it was also unclear whether the effect of fat-feeding and obesity on glycogen synthase was secondary to hyperglycaemia or hyperinsulinaemia, and whether muscle glycogen synthesis was reduced in an indirect manner due to diminished glucose uptake,
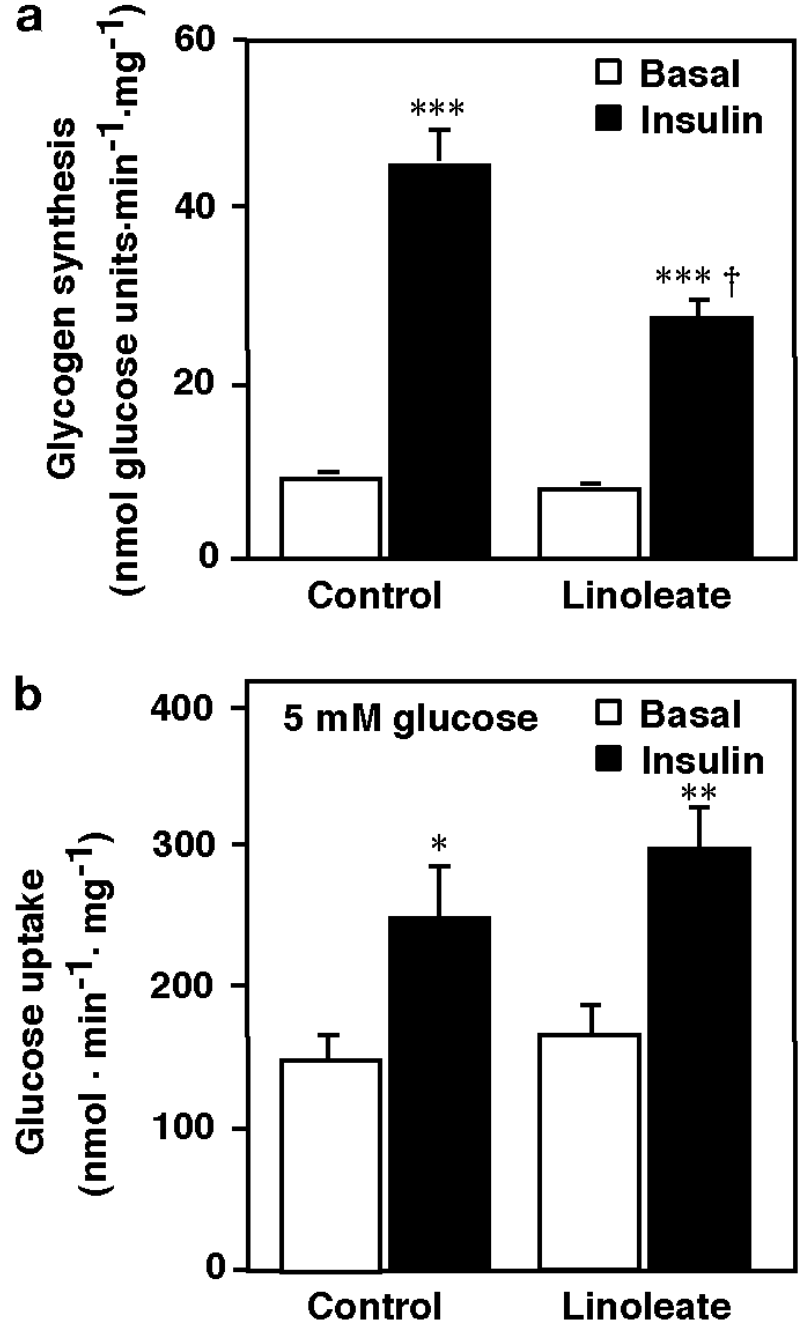

Figure 3 Effect of linoleate on glycogen synthesis and glucose uptake in L6 skeletal muscle cells. (a) Basal and insulin-stimulated glycogen synthesis was determined in control myotubes and in myotubes pretreated for $16 \mathrm{~h}$ with linoleate. Results shown are means from three experiments, each carried out in triplicate. $t$-test, ${ }_{* * *} P<0 \cdot 001$, insulin-stimulated vs basal; $+P<0 \cdot 001$, linoleate-treated insulin-stimulated vs control insulin-stimulated. (b) Basal and insulin-stimulated glucose uptake were determined in control and lipid-pretreated myotubes under the same conditions as for (a). Results shown are means from two experiments, each carried out in triplicate. ${ }^{*} P<0 \cdot 05,{ }^{*} P<0 \cdot 025$, insulin-stimulated vs basal.

we pursued these findings in more detail, using lipidpretreated myotubes as a cell model of insulin resistance.

We firstly measured glycogen synthesis in fully differentiated L6 rat myotubes which had been pretreated for $16 \mathrm{~h}$ in the absence or presence of the unsaturated FFA linoleate, the major FFA present in the high-fat diet (Storlien et al. 1986). Linoleate pretreatment caused $40 \%$ inhibition in the insulin-stimulated component of glycogen synthesis (Fig. 3a), consistent with the effect of fat-feeding on rat muscle (Table 1). To determine the 
a

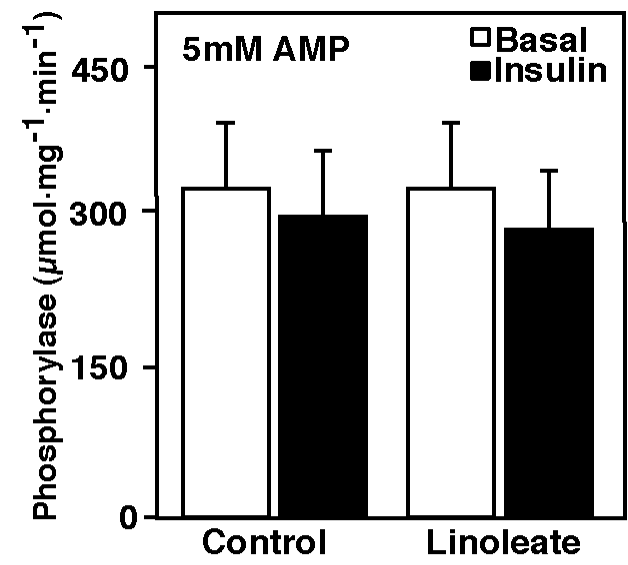

b
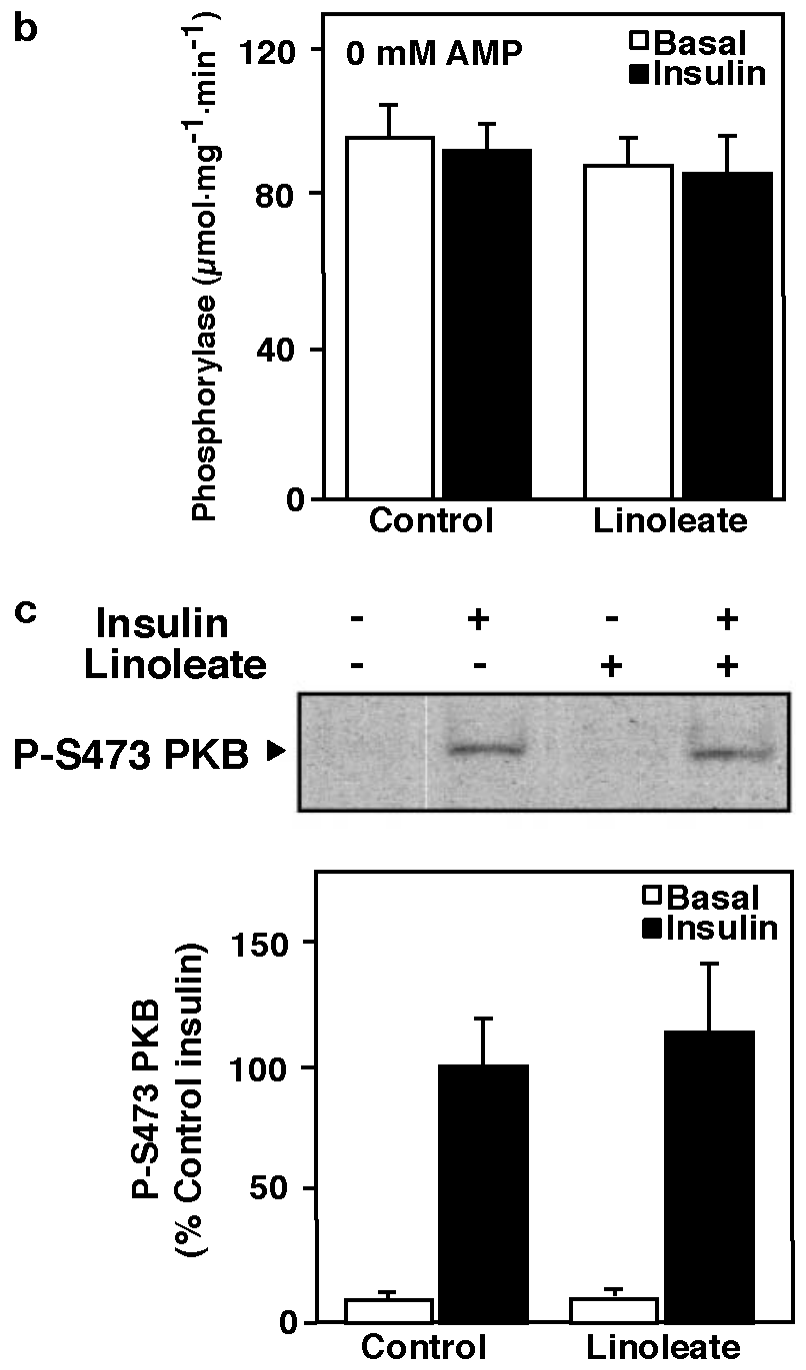

www.endocrinology-journals.org possible contribution of reduced intracellular glucose availability, we investigated the effect of linoleate on glucose uptake by the L6 myotubes. We measured glucose uptake in the presence of physiological glucose concentrations $(5 \mathrm{mM})$, identical to the conditions under which glycogen synthesis itself had been determined. Glucose uptake was linear over $1 \mathrm{~h}$ (not shown), and there was no change in either basal or insulin-stimulated glucose uptake (Fig. 3b). In addition, while glycogen synthase activity depends in part on the concentration of its major allosteric activator G6P, we did not observe significant differences in the steady-state levels of G6P upon insulin stimulation, in either control or lipid-treated cells (fold increase: control, $1 \cdot 0 \pm 0 \cdot 20$; linoleate-treated, $0 \cdot 94 \pm 0 \cdot 10, n=4$ ) under these conditions, indicating that elevations in G6P levels were not necessary to promote insulin-stimulated glycogen synthesis.

We next determined whether linoleate pretreatment altered the activity of glycogen phosphorylase, because the rate of glycogen synthesis we have measured here is a net result of the opposing effects of glycogen synthesis and breakdown. Glycogen phosphorylase was assayed in the presence or absence of the allosteric activator AMP, which enabled us to examine the total levels and activation state of the enzyme respectively. We did not, however, observe any alterations in glycogen phosphorylase in response either to FFA pretreatment or to insulin stimulation (Fig. 4a and b), indicating that upregulation or activation of this enzyme did not account for the reduced glycogen synthesis. We also examined the effect of linoleate pretreatment on insulin signalling through the PKB pathway in L6 myotubes, because this plays an important role in the regulation of glycogen synthase by insulin. As previously reported in C2C12 muscle cells (Schmitz-Peiffer et al. 1999), linoleate did not inhibit phosphorylation of either PKB (Fig. 4c) or GSK-3 (not shown), indicating that the inhibition of glycogen synthesis by the unsaturated FFA is not mediated through these components of insulin signalling. Taken together, the results shown in Figs 3 and 4 suggest that the defect responsible for diminished glycogen synthesis lies closer to glycogen synthase itself, consistent with a role for the compartmentalization of the enzyme.

To compare the cellular localization of glycogen synthase in L6 cells with that we had observed in rat skeletal muscle, myotube extracts were also fractionated by

Figure 4 Effect of linoleate on glycogen phosphorylase and PKB. The activity of glycogen phosphorylase was determined in homogenates, in either the presence (a) or absence (b) of $5 \mathrm{mM}$ AMP. Results shown are combined means from six independent experiments, each carried out in duplicate. (c) Basal and insulin-stimulated PKB Ser473 phosphorylation was determined in lysates from control and lipid-pretreated myotubes by immunoblotting with a phospho-specific antibody. The results of densitometry from three independent experiments, each carried out in triplicate, are shown. 
centrifugation and detergent solubilization to generate subcellular compartments. The TIF generated from cells was physically more amenable to biochemical analyses. By immunoblotting, we found that glycogen synthase protein was again recovered, mostly in the TIF, while a small
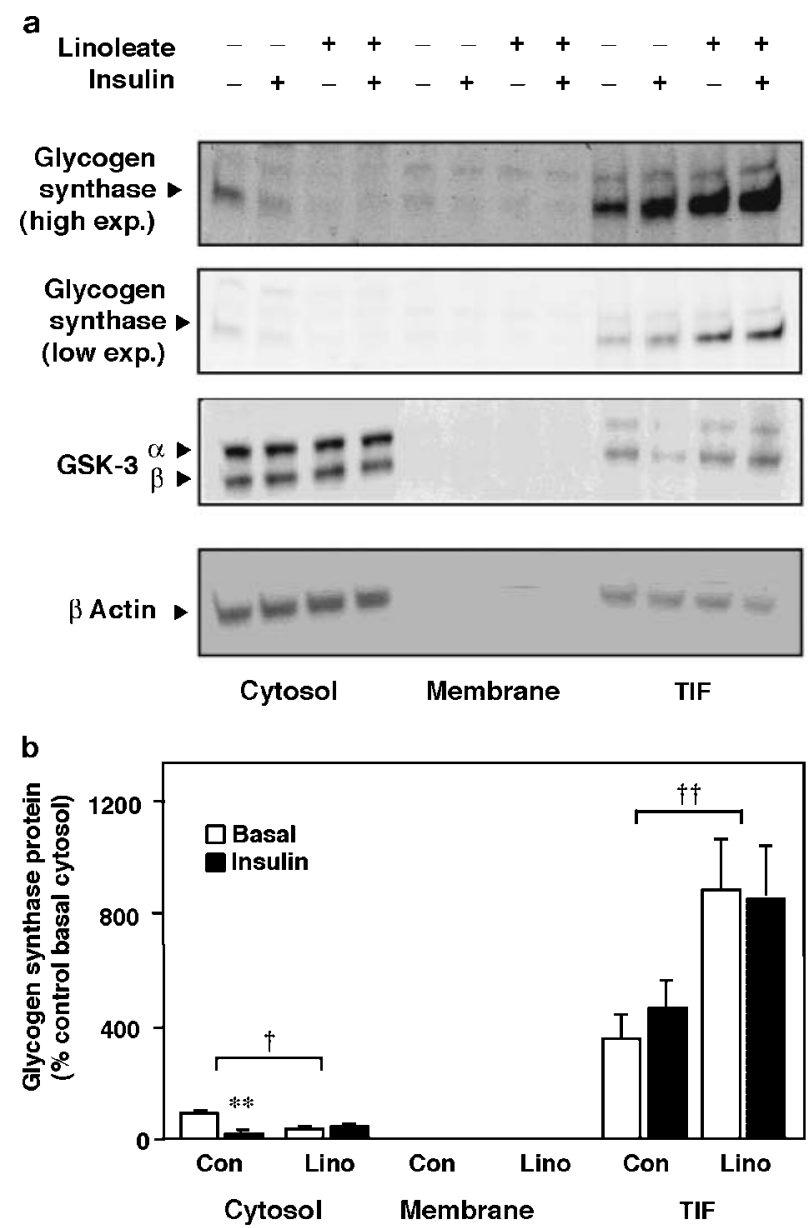

c

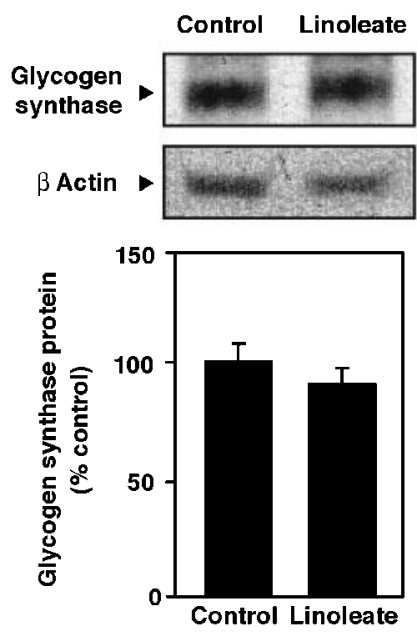

Journal of Endocrinology (2006) 188, 11-23 proportion was recovered in the cytosolic fraction, and levels in the solubilized-membrane fraction were undetectable (Fig. 5a and b). Importantly, we observed changes in the partitioning of the enzyme in response to both insulin stimulation and linoleate treatment, broadly similar to the changes seen in rat muscle. Glycogen synthase from insulin-stimulated control myotubes appeared to translocate from the cytosol to the TIF. In addition, linoleate pretreatment reduced the amount of cytosolic glycogen synthase even prior to insulin treatment, and greatly increased its recovery in the TIF (Fig. 5a and $b$ ). Such alterations in protein recovery were not observed in immunoblots of GSK-3 or $\beta$-actin (Fig. 5a), indicating that they were specific for glycogen synthase.

The quantity of glycogen synthase recovered in the TIF from linoleate-treated cells appeared greater than that apparently translocating from the cytosolic fraction (Fig. 5a and b). Total glycogen synthase protein levels in homogenates, however, were unaffected by linoleate (Fig. 5c). To address this discrepancy, and to compare the distribution of activity in L6 myotubes with that observed in rat muscles, we also assayed glycogen synthase activity in fractions from both control and linoleate-treated cells. Total activities (Fig. 6a) were in good agreement with the data from immunoblots of glycogen synthase protein (Fig. 5b), in that both insulin and linoleate caused changes in recovery of enzyme activity in the cytosolic fraction and the TIF. In this case, loss of activity in the cytosol was more comparable with the increased activity measured in the TIF, suggesting that the enzyme was indeed translocating in response to both insulin and linoleate.

To determine the activation state of glycogen synthase in the different fractions, we also measured the activity in the presence of a more physiological G6P concentration (Fig. 6b), and expressed this as a proportion of the total activity to give the fractional velocity of the enzyme (Fig. 6c). Insulin tended to increase the activity observed in the cytosol from control cells (Fig. 6b) despite the loss of total enzyme from this fraction (Fig. 6a), suggesting that

\footnotetext{
Figure 5 Effect of linoleate on glycogen synthase protein partitioning in L6 skeletal muscle cells. (a) Myotubes were pretreated in the absence or presence of linoleate for $16 \mathrm{~h}$ and incubated without or with insulin for $1 \mathrm{~h}$. Whole-cell lysates were fractionated to obtain cytosolic, solubilized-membrane and Triton-insoluble fractions. Samples were subjected to immunoblotting with either glycogen synthase (high and low exposures of the same blot are shown), GSK-3 or $\beta$-actin antibodies as indicated. (b) The results of densitometry of glycogen synthase bands from three independent experiments carried out in duplicate are shown. ${ }^{* *} t$-test, $P<0 \cdot 005$, effect of insulin on cytosolic glycogen synthase; ANOVA, $+P<0 \cdot 05$, $+\uparrow P<0 \cdot 01$, effect of lipid on glycogen synthase recovery. (c) Whole-myotube lysates were subjected to immunoblotting with antiglycogen synthase or anti- $\beta$-actin antibodies as indicated. The means from densitometry of three independent experiments done in triplicate are shown, after correction of glycogen synthase for $\beta$-actin loading (lower panel).
} 

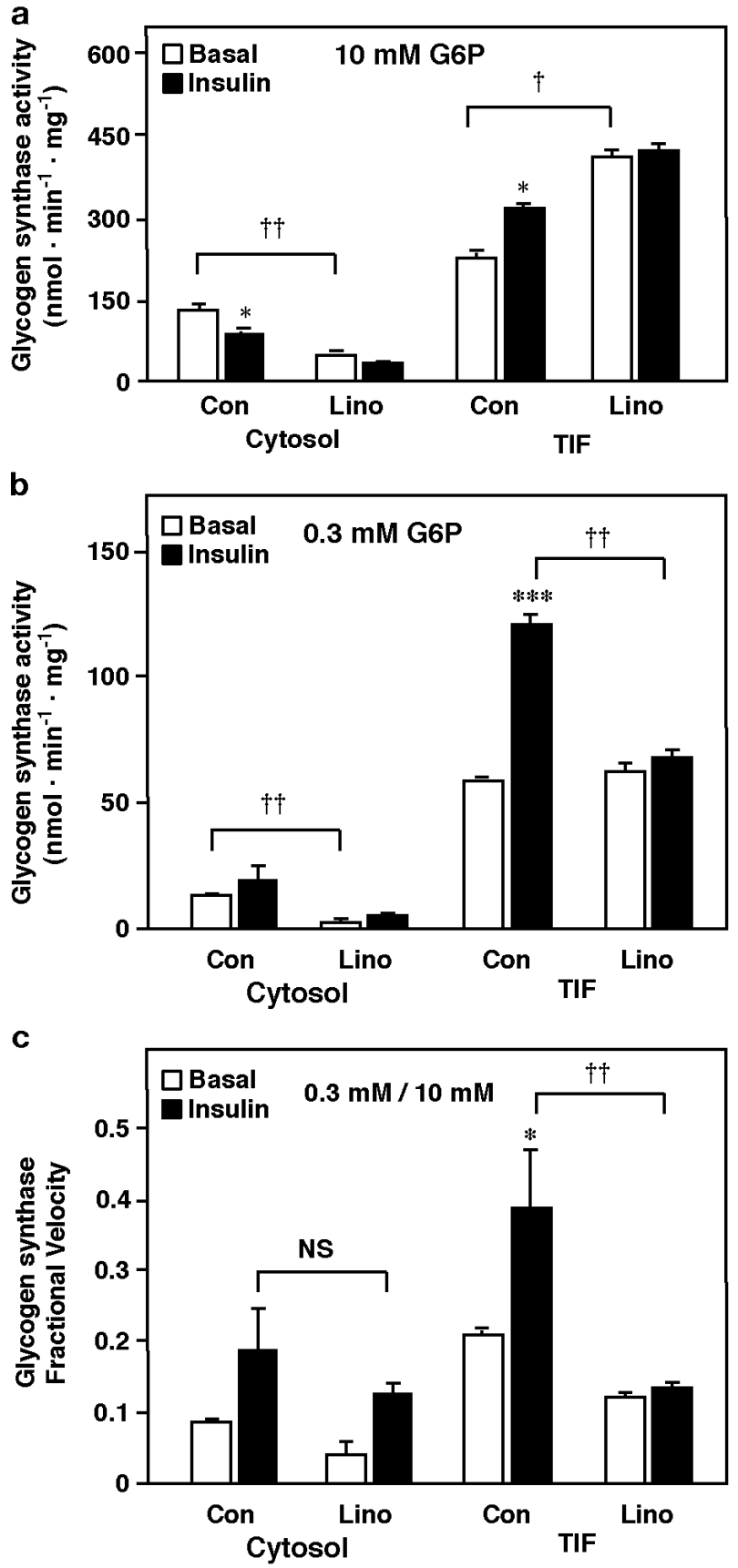

Figure 6 Effect of linoleate on recovery of glycogen synthase activity in subcellular fractions from L6 cells. Myotubes were treated and fractionated as given in the legend for Fig. 5, and fractions assayed for glycogen synthase activity in the presence of $10 \mathrm{mM}$ G6P (a) or $0.3 \mathrm{mM}$ G6P (b). (c) The fractional velocity of glycogen synthase was calculated for each fraction as the ratio of activity measured at $0.3 \mathrm{mM}$ G6P to that measured at $10 \mathrm{mM}$ G6P. The means from three independent experiments are shown. $t$-tests, ${ }^{*} P<0 \cdot 05,{ }^{*} * * P<0 \cdot 005$, effect of insulin; $+P<0 \cdot 02$,

$+\dagger P<0 \cdot 005$, effect of lipid. the hormone caused activation of cytosolic glycogen synthase (Fig. 6c), as well as translocation, to give a net increase. Increased activity was also observed in the TIF from insulin-stimulated control cells (Fig. 6b), in part due to the increased amount of the enzyme present (Fig. 6a) but also due to activation (Fig. 6c). In contrast, the glycogen synthase activity measured in the TIF from linoleate-pretreated cells (Fig. 6b) was lower than that expected from the total amount of enzyme present (Fig. 6a), and was not increased upon insulin stimulation (Fig. 6b and c). In fact, lipid pretreatment significantly reduced the activation state of the enzyme observed in the TIF upon insulin stimulation relative to that in the TIF from control cells (Fig. 6c), even though the insulinstimulated activation state of the remaining cytosolic glycogen synthase was not different to that in control cells.

The data presented in Fig. 6 suggested that lipid pretreatment caused the translocation of glycogen synthase to an insulin-insensitive pool in the TIF. Because an insulin-sensitive pool from control cells was recovered in the same subcellular fraction, we examined potential causes of the lipid-dependent redistribution of the enzyme and attempted to distinguish biochemically between the pools. Increased lipid availability can increase flux through the hexosamine pathway and promote protein glycosylation (Hawkins et al. 1997), which has been reported to modulate glycogen synthase (Parker et al. 2003). No evidence, however, for such a modification was observed in immunoprecipitates of the enzyme with an antibody specific for $\mathrm{O}$-glycosylated protein in subsequent immunoblots (not shown). In addition, we were unable to determine any changes in proteins associated with glycogen synthase in immunoprecipitates, after SDS-PAGE and silver staining (not shown). We also attempted to separate the two pools in the TIF by sequential solubilization involving Triton X-100-, SDS- and urea-containing buffers. No further fractionation, however, of the enzyme was achieved (not shown).

Immunoblotting using antibodies specific for the glycogen targeting protein PTG indicated that this was mostly recovered in the cytosol from L6 myotubes, with a minor proportion located in the TIF (not shown), while the targeting protein $R_{G L}\left(G_{M}\right)$ was not detected in L6 cell fractions, but was observed in the membrane fraction from skeletal muscle. Both proteins failed to show alterations distribution in response to increased lipid availability (not shown), suggesting that they did not mediate the change in the recovery of glycogen synthase through their own translocation.

Finally, because the translocation of glycogen synthase from a cytosolic fraction has been linked to alterations in cellular glycogen content in adipocytes (Brady et al. 1999) and skeletal muscle (Nielsen et al. 2001), we investigated the relationship between the recovery of the enzyme in different fractions from L6 cells and the distribution and synthesis of glycogen itself. Firstly, we determined the 

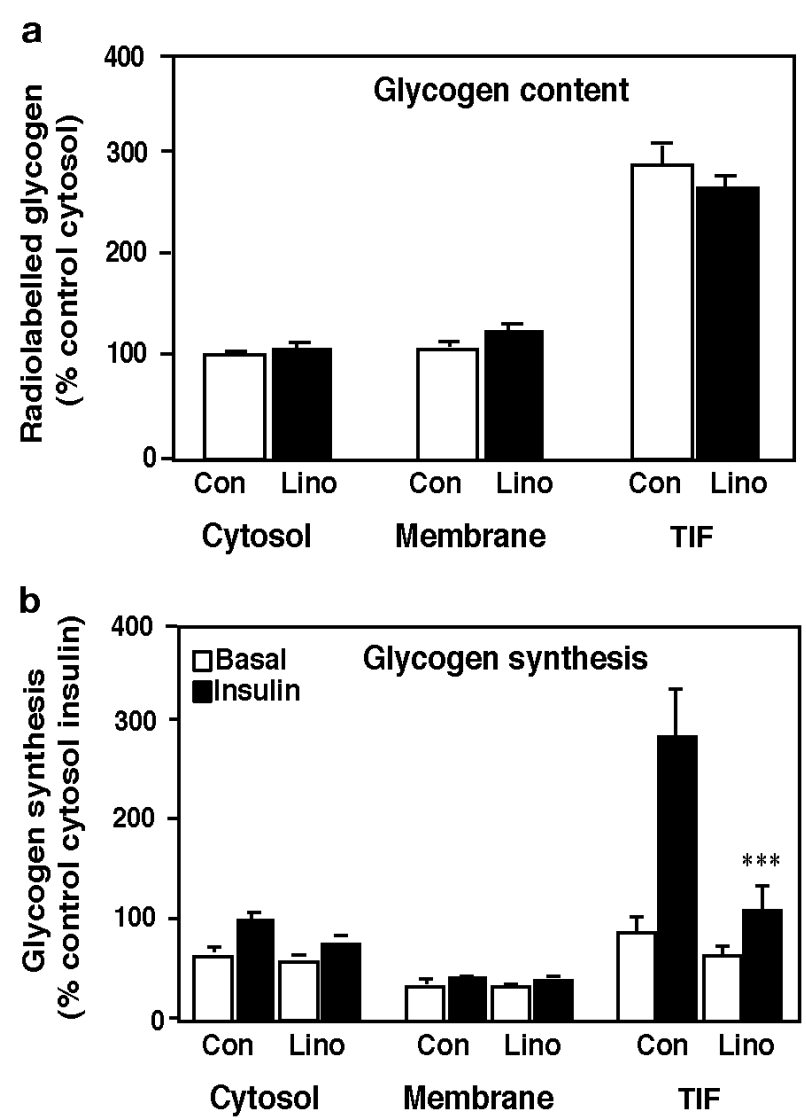

Figure 7 Effect of linoleate on steady-state glycogen content and acute glycogen synthesis in subcellular fractions. (a) Myotubes were incubated for $48 \mathrm{~h}$ in media containing $\mathrm{D}-\left[\mathrm{U}-{ }^{14} \mathrm{C}\right]$ glucose before treatment with linoleate for $16 \mathrm{~h}$, also in the presence of $\mathrm{D}-\left[\mathrm{U}-{ }^{14} \mathrm{C}\right] \mathrm{glucose}$, and fractionated as given in the legend for Fig. 5. Radiolabelled glycogen was determined in each fraction. Results shown are combined means from three independent experiments, each carried out in triplicate. (b) Myotubes were pretreated without or with linoleate for $16 \mathrm{~h}$ and incubated for $1 \mathrm{~h}$ in the absence or presence of insulin for the measurement of glycogen synthesis from D-[U- $\left.{ }^{14} \mathrm{C}\right]$ glucose. Radiolabelled glycogen was determined in each subcellular fraction. Results shown are means from five independent experiments, each carried out in triplicate. t-test, ${ }^{* *} P<0 \cdot 001$, control insulin-stimulated vs linoleate-treated insulin-stimulated.

effect of linoleate on steady state glycogen levels. Upon fractionation of the cells, the greatest amount of glycogen was found in the TIF, but there was no effect of the FFA on total glycogen content in any fraction (Fig. 7a), indicating that this did not play a role in the repartitioning of the enzyme. Next, we examined the subcellular distribution of the glycogen synthesized over $1 \mathrm{~h}$ in response to insulin stimulation in control and lipid-pretreated myotubes (previously measured in whole lysates (Fig. 3a)). In this case, glycogen synthesized in response to insulin was recovered almost exclusively in the TIF, and this component was greatly reduced in linoleate-pretreated cells
(Fig. 7b). Together with the data shown in Fig. 6, this suggests that while newly synthesized glycogen is recovered in the TIF, the component of glycogen synthase initially located in the cytosol plays a significant role and that the lipid-induced redistribution of glycogen synthase from the cytosol to the insoluble fraction renders it unable to participate in insulin-stimulated glycogen synthesis.

\section{Discussion}

The activity of glycogen synthase in muscle cells is dependent upon several factors. In addition to the importance of the phosphorylation state of the enzyme, the concentration of its allosteric activator G6P and the actions of the glycogen-targeting proteins, the role of cellular localization is becoming apparent (FernandezNovell et al. 1992, Brady et al. 1999, Nielsen et al. 2001). We here present evidence supporting the novel hypothesis that lipid-induced insulin resistance at the level of glycogen synthesis is explained at least in part by a repartitioning of glycogen synthase to an insulin-insensitive pool. Our observations were made in three distinct but wellcharacterized models of muscle insulin resistance, involving fat-fed rats, obese $d b / d b$ mice and lipid-treated muscle cells.

The insulin-dependent translocation of glycogen synthase which we have observed in muscle of chow-fed rats and in control cells agrees with previous studies (Brady et al. 1999, Jensen et al. 2000), and in this case the enzyme is probably associated either with cytoskeletal elements (Garcia-Rocha et al. 2001) or with glycogen itself (Brady et al. 1999, Nielsen et al. 2001). An insulin-dependent association with glycogen is supported by the fact that the TIF contained the largest amount of total glycogen, and that glycogen synthesized in response to the hormone was mostly recovered in this fraction. Furthermore, while we observed translocation in rat muscle after a hyperinsulinaemic clamp, and in control cells upon 1-h insulin stimulation, as consistent with the co-sedimentation of glycogen synthase with newly synthesized, large, insoluble glycogen molecules, we did not observe such translocation after only 10-min insulin stimulation (data not shown), when smaller, nascent glycogen molecules might be recovered in the cytosol. It should be noted that although we observed changes in the recovery of glycogen synthase in different subcellular fractions, these could indicate alterations in the association of the enzyme with protein or carbohydrate complexes, rather than in cellular localization, as previously reported in response to other stimuli (Ferrer et al. 1997, Skurat et al. 1997, Garcia-Rocha et al. 2001, Nielsen et al. 2001, Ou et al. 2005). Thus, although immunoblotting and in vitro assays indicated that the major proportion of glycogen synthase is recovered in the TIF even in the absence of lipid, it is possible that in intact cells and muscle this pool is inhibited 
by association with glycogen (Nielsen et al. 2001) and does not participate efficiently in glycogen synthesis, increasing the significance of the soluble pool.

Although fat-feeding, obesity or linoleate pretreatment appeared to cause a similar redistribution of glycogen synthase to the TIF, the pool of the enzyme increased in the TIF by lipid was probably distinct from that increased by insulin. Firstly, glycogen synthase appearing in the TIF in a lipid-dependent manner exhibited a low fractional velocity and was resistant to insulin; second, the redistribution was associated with an inhibition of insulinstimulated glycogen synthesis, in direct contrast to the repartitioning caused by insulin itself. This is consistent with the sequestration of glycogen synthase in the TIF by lipid oversupply in such a way that it is no longer sensitive to activation by insulin. The amount of cytosolic glycogen synthase is thus reduced, and we hypothesize that this apparently minor pool of the enzyme is necessary for the full increase in glycogen synthesis to occur in response to the hormone.

Our observations are thus similar to those made with adipocytes (Jensen et al. 2000), in which insulin reduced a minor pool of glycogen synthase present in lighter fractions derived from sucrose gradients, and promoted its recovery in a denser fraction. Insulin pretreatment, which was associated with diminished glycogen synthesis upon subsequent insulin stimulation, caused prior partitioning of the enzyme to the denser fraction. It was concluded that a minor component of glycogen synthase was responsible for most of the newly synthesized glycogen in adipocytes, and that correct basal localization was required for activation of the enzyme by insulin (Jensen et al. 2000). Our data support a similar situation in muscle, in that the cytosolic component may contribute most to glycogen synthesis, and furthermore suggest that lipid oversupply, like insulin pretreatment, can lead to a sequestration of the enzyme that contributes to a reduction in subsequent, insulin-stimulated glycogen synthesis. A possible explanation is that this redistribution reduces access by PP1 and hence limits activation normally promoted by dephosphorylation of the enzyme. Such a mechanism is supported by the lack of effect of linoleate on the insulin-stimulated activation of $\mathrm{PKB}$, suggesting that the pathway downstream of this signalling component, which reduces further phosphorylation of glycogen synthase by inhibition of GSK-3, is still intact.

While we were unable to determine the mechanism by which lipid oversupply causes such a redistribution, we were able to discount a simple role for glycogen accumulation. Firstly, the glycogen content of rat skeletal muscle was not significantly increased by fat-feeding; second, linoleate pretreatment did not alter the steady-state levels of glycogen in any subcellular fraction from L6 myotubes, despite an increase in the partitioning of the enzyme in the TIF in each case. We were also unable to find evidence for glycosylation or the association of a binding partner.
We cannot, however, rule out a post-translational modification, such as phosphorylation of the enzyme or its targeting proteins, which might affect its binding. Indeed, a reason for the discrepancy between the amounts of glycogen synthase protein appearing in the TIF of lipid-treated cells and that translocating from the cytosol as determined by immunoblotting (Fig. 5a) may be an alteration in antibody recognition of glycogen synthase following such a post-translational modification, as recently reported (Ou et al. 2005). Alternatively, direct association of glycogen synthase with lipid species in intact cells may promote its inhibition and sedimentation, as described for phosphatidic acid phosphohydrolase-1 (Elabbadi et al. 2005).

Comparison of the rates of glucose uptake (approximately $300 \mathrm{nmol}$ per min/mg) (Fig. 3c) and glycogen synthesis (less than $30 \mathrm{nmol}$ per min/mg) (Fig. 3a) in linoleate-pretreated, insulin-stimulated cells suggested that glucose uptake by the myotubes did not limit glycogen synthesis under the conditions employed here. Furthermore, the lack of effect of insulin on steady-state G6P levels measured in these cells indicates that the observed increase in glycogen synthesis in response to insulin in control cells (Fig. 3a) cannot be attributed to elevations in this allosteric activator upon increased glucose uptake. Importantly, therefore, the inhibitory effect of linoleate on insulin-stimulated glycogen synthesis cannot be explained by a reduced effect of insulin on G6P concentration. Similarly, previous studies have also shown that G6P content is not reduced in muscle of fat-fed rats (Kim et al. 1996, 2000). In any case, the differing activation states of cytosolic and TIF-associated glycogen synthase we have observed in lipid-treated myotubes indicate that the cellular G6P concentration cannot be solely responsible for alterations in glycogen synthesis. Taken together, these findings suggest that a primary defect at the level of glycogen synthase contributes to the diminished glycogen synthesis observed in the presence of lipid, strengthening the case for a role of compartmentalization.

The relative importance of the rate of glucose uptake and the activity of glycogen synthase in the determination of the rate of glycogen synthesis has been controversial, and it is likely that either factor can play an overriding role under specific physiological circumstances (Fisher et al. 2002). Thus, while NMR studies have indicated that glucose transport can be rate-limiting (Roden et al. 1996, Dresner et al. 1999), work in skeletal muscle fibres has indicated that control of glycogen synthesis is shared between glucose transport and glycogen synthase (Azpiazu et al. 2000). An impairment of glycogen synthase activity also contributes to the diminished glycogen synthesis seen in lipid-infused human subjects at higher free fatty acid levels (Boden et al. 1994).

In summary, while previous work has suggested that exposure of muscle to increased lipid levels does not greatly affect the activity of glycogen synthase (Johnson 
et al. 1992, Kelley et al. 1993, Boden et al. 1994, Stark et al. 2000, Huang et al. 2003), by using a subcellular fractionation protocol we have been able to demonstrate a novel effect of lipid on the partitioning of the enzyme, which depletes a small but probably important soluble pool. While long-term exposure of muscles to increased lipid supply may involve some mechanisms distinct from those induced by culturing cells for $16 \mathrm{~h}$ with FFA, our in vivo data concerning the inhibition of glucose disposal and the partitioning of glycogen synthase in fat-fed rats and $d b / d b$ mice are broadly similar to the inhibitory effects of linoleate we observed in L6 myotubes, indicating that these are not peculiar to cultured cells. While the myotubes are not an exact representation of muscle tissue, an advantage of the model we have employed is the ability to define conditions for the study of glycogen synthase under which the contribution of lipid effects on glucose transport and phosphorylation can be discounted. This study has thus indicated a new aspect of lipid-induced insulin resistance at the level of glycogen synthesis, although further work is required to elucidate the mechanism of glycogen synthase repartitioning.

\section{Acknowledgements}

This work was funded by grants from the National Health and Medical Research Council of Australia (CSP), and the Diabetes Australia Research Trust (CSP, JMY), and by an Australian Postgraduate Award (AJT). The authors declare that there is no conflict of interest that would prejudice the impartiality of this scientific work.

\section{References}

Azpiazu I, Manchester J, Skurat AV, Roach PJ \& Lawrence JC 2000 Control of glycogen synthesis is shared between glucose transport and glycogen synthase in skeletal muscle fibers. American Journal of Physiology 278 E234-E243.

Benzo CA \& Stearns SB 1982 Glycogen synthase and phosphorylase activities in skeletal muscle from genetically diabetic $(\mathrm{db} / \mathrm{db})$ mice. Hormone and Metabolic Research 14 130-133.

Boden G, Chen X, Ruiz J, White JV \& Rossetti L 1994 Mechanisms of fatty acid-induced inhibition of glucose uptake. Journal of Clinical Investigation 93 2438-2446.

Brady MJ, Kartha PM, Aysola AA \& Saltiel AR 1999 The role of glucose metabolites in the activation and translocation of glycogen synthase by insulin in 3T3-L1 adipocytes. Journal of Biological Chemistry 274 27497-27504.

Cazzolli R, Craig DL, Biden TJ \& Schmitz-Peiffer C 2002 Inhibition of glycogen synthesis by fatty acid in C2C12 muscle cells is independent of PKC $-\alpha,-\varepsilon$, and $-\theta$. American Journal of Physiology 282 E1204-E1213.

Cohen P, Alessi DR \& Cross D 1997 PDK1, one of the missing links in insulin signal transduction? FEBS Letters 410 3-10.

Coleman DL 1978 Obese and diabetes: two mutant genes causing diabetes-obesity syndromes in mice. Diabetologia 14 141-148.

Dresner A, Laurent D, Marcucci M, Griffin ME, Dufour S, Cline GW, Slezak LA, Andersen DK, Hundal RS, Rothman DL et al.
1999 Effects of free fatty acids on glucose transport and IRS-1-associated phosphatidylinositol 3-kinase activity. Journal of Clinical Investigation 103 253-259.

Elabbadi N, Day CP, Gamouh A, Zyad A \& Yeaman SJ 2005 Relationship between the inhibition of phosphatidic acid phosphohydrolase- 1 by oleate and oleoyl-CoA ester and its apparent translocation. Biochimie 87 437-443.

Fernandez-Novell JM, Arino J, Vilaro S \& Guinovart JJ 1992 Glucose induces the translocation and the aggregation of glycogen synthase in rat hepatocytes. Biochemical Journal 281 443-448.

Ferrer JC, Baque S \& Guinovart JJ 1997 Muscle glycogen synthase translocates from the cell nucleus to the cytosol in response to glucose. FEBS Letters 415 249-252.

Ferrer JC, Favre C, Gomis RR, Fernandez-Novell JM, Garcia-Rocha M, de la Iglesia N, Cid E \& Guinovart JJ 2003 Control of glycogen deposition. FEBS Letters 546 127-132.

Fisher JS, Nolte LA, Kawanaka K, Han DH, Jones TE \& Holloszy JO 2002 Glucose transport rate and glycogen synthase activity both limit skeletal muscle glycogen accumulation. American Journal of Physiology 282 E1214-E1221.

Garcia-Rocha M, Roca A, de la Iglesia N, Baba O, Fernandez-Novell JM, Ferrer JC \& Guinovart JJ 2001 Intracellular distribution of glycogen synthase and glycogen in primary cultured rat hepatocytes. Biochemical Journal 357 17-24.

Gilboe DP, Larson KL \& Nuttall FQ 1972 Radioactive method for the assay of glycogen phosphorylases. Analytical Biochemistry 47 $20-27$.

Green AR, Aiston S, Greenberg CC, Freeman S, Poucher SM, Brady MJ \& Agius L 2004 The glycogenic action of protein targeting to glycogen in hepatocytes involves multiple mechanisms including phosphorylase inactivation and glycogen synthase translocation. Journal of Biological Chemistry 279 46474-46482.

Hawkins M, Barzilai N, Liu R, Hu MZ, Chen W \& Rossetti L 1997 Role of the glucosamine pathway in fat-induced insulin resistance. Journal of Clinical Investigation 99 2173-2182.

Huang XD, Hansson M, Laurila E, Ahren B \& Groop L 2003 Fat feeding impairs glycogen synthase activity in mice without effects on its gene expression. Metabolism 52 535-539.

Hughes WE \& Parker PJ 2001 Endosomal localization of phospholipase D 1a and $1 \mathrm{~b}$ is defined by the C-termini of the proteins, and is independent of activity. Biochemical Journal 356 $727-736$.

James DE, Jenkins AB \& Kraegen EW 1985 Heterogeneity of insulin action in individual muscles in vivo: euglycemic clamp studies in rats. American Journal of Physiology 248 E567-E574.

Jensen TC, Crosson SM, Kartha PM \& Brady MJ 2000 Specific desensitization of glycogen synthase activation by insulin in 3T3-L1 adipocytes - connection between enzymatic activation and subcellular localization. Journal of Biological Chemistry 275 40148-40154.

Johnson AB, Argyraki M, Thow JC, Cooper BG, Fulcher G \& Taylor R 1992 Effect of increased free fatty-acid supply on glucose-metabolism and skeletal-muscle glycogen-synthase activity in normal man. Clinical Science 82 219-226.

Kelley DE, Mokan M, Simoneau JA \& Mandarino LJ 1993 Interaction between glucose and free fatty acid metabolism in human skeletal muscle. Journal of Clinical Investigation 92 91-98.

Kim CH, Youn JH, Park JY, Hong SK, Park KS, Park SW, Suh KI \& Lee KU 2000 Effects of high-fat diet and exercise training on intracellular glucose metabolism in rats. American Journal of Physiology 278 E977-E984.

Kim JK, Wi JK \& Youn JH 1996 Metabolic impairment precedes insulin resistance in skeletal muscle during high-fat feeding in rats. Diabetes 45 651-658.

Kochan RG, Lamb DR, Reimann EM \& Schlender KK 1981 Modified assays to detect activation of glycogen synthase following exercise. American Journal of Physiology 240 E197-E202. 
Kraegen EW, James DE, Storlien LH, Burleigh KM \& Chisholm DJ 1986 In vivo insulin resistance in individual peripheral tissues of the high fat fed rat: assessment by euglycemic clamp plus deoxyglucose administration. Diabetologia 29 192-198.

McGarry JD 1992 What if Minkowski had been ageusic? An alternative angle on diabetes. Science 258 766-770.

Michal G 1984 D-Glucose 6-phosphate and D-fructose 6-phosphate. In Methods of Enzymatic Analysis (3rd edn), pp. 191-198. Ed HU Bergmeyer. Weinheim: Verlag Chemie.

Mitsumoto Y \& Klip A 1992 Development regulation of the subcellular distribution and glycosylation of GLUT1 and GLUT4 glucose transporters during myogenesis of L6 muscle cells. Journal of Biological Chemistry 267 4957-4962.

Newgard CB, Brady MJ, O’Doherty RM \& Saltiel AR 2000 Organizing glucose disposal - emerging roles of the glycogen targeting subunits of protein phosphatase-1. Diabetes 49 1967-1977.

Nielsen JN, Derave W, Kristiansen S, Ralston E, Ploug T \& Richter EA 2001 Glycogen synthase localization and activity in rat skeletal muscle is strongly dependent on glycogen content. Journal of Physiology $\mathbf{5 3 1}$ 757-769.

Oakes ND, Kennedy CJ, Jenkins AB, Laybutt DR, Chisholm DJ \& Kraegen EW 1994 A new antidiabetic agent, BRL 49653, reduces lipid availability and improves insulin action and glucoregulation in the rat. Diabetes 43 1203-1210.

Ou H, Yan L, Osmanovic S, Greenberg CC \& Brady MJ 2005 Spatial reorganization of glycogen synthase upon activation in 3T3-L1 adipocytes. Endocrinology 146 494-502.

Parker GJ, Lund KC, Taylor RP \& McClain DA 2003 Insulin resistance of glycogen synthase mediated by $\mathrm{O}-$ linked $\mathrm{N}$-acetylglucosamine. Journal of Biological Chemistry 278 10022-10027.

Randle PJ 1998 Regulatory interactions between lipids and carbohydrates: the glucose fatty acid cycle after 35 years. Diabetes/Metabolism Reviews 14 263-283.

Roden M, Price TB, Perseghin G, Petersen KF, Rothman DL, Cline GW \& Shulman GI 1996 Mechanism of free fatty acid-induced insulin resistance in humans. Journal of Clinical Investigation 97 2859-2865.

Schmitz-Peiffer C 2000 Signalling aspects of insulin resistance in skeletal muscle: mechanisms induced by lipid oversupply. Cellular Signalling 12 583-594.

Schmitz-Peiffer C, Browne CL, Oakes ND, Watkinson A, Chisholm DJ, Kraegen EW \& Biden TJ 1997 Alterations in the expression and cellular localization of protein kinase $\mathrm{C}$ isozymes $\varepsilon$ and $\theta$ are associated with insulin resistance in skeletal muscle of the high-fat-fed rat. Diabetes 46 169-178.

Schmitz-Peiffer C, Craig DL \& Biden TJ 1999 Ceramide generation is sufficient to account for the inhibition of the insulin-stimulated PKB pathway in C2C12 skeletal muscle cells pretreated with palmitate. Journal of Biological Chemistry 274 24202-24210.

Skurat AV, Lim SS \& Roach PJ 1997 Glycogen biogenesis in rat 1 fibroblasts expressing rabbit muscle glycogenin. European Journal of Biochemistry 245 147-155.

Stark AH, Timar B \& Madar Z 2000 Adaptation of Sprague Dawley rats to long-term feeding of high fat or high fructose diets. European Journal of Nutrition 39 229-234.

Storlien LH, James DE, Burleigh KM, Chisholm DJ \& Kraegen EW 1986 Fat feeding causes widespread in vivo insulin resistance, decreased energy expenditure and obesity in the rat. American Journal of Physiology 251 E576-E583.

Ye JM, Iglesias MA, Watson DG, Ellis B, Wood L, Jensen PB, Sorensen RV, Larsen PJ, Cooney GJ, Wassermann K et al. 2003 PPAR alpha/gamma ragaglitazar eliminates fatty liver and enhances insulin action in fat-fed rats in the absence of hepatomegaly. American Journal of Physiology 284 E531-E540.

Received in final form 28 September 2005

Accepted 11 October 2005

Made available online as an Accepted Preprint

9 September 2005 